\title{
THE PRACTICE OF NEUROSOMNOLOGY
}

\author{
ANTONIO CULEBRAS *
}

\begin{abstract}
SUMMARY - Since the application of electrophysiologic methods borrowed from the EEG laboratory to the study of sleeping huntans, sleep disorders medicine has acquired the scientific organization necessary for its acceptance in the modern clinic. Although still in evolution, the medical science of sleep is becoming increasingly linked to the functions of the brain, carving in the territory of neurology a parcel of jts own that we call neurosomnology. Patients referred to the sleep disorders specialist receive an initial evaluation that includes general medical, neurologic and when appropriate other specialized examinations. In the sleep laboratory patients undergo nocturnal and daytime polysomnographic recordings which incorporate electrical brain activity, eye movements, muscle tone, EKG, limb movements, regpirations, oximetry and in special circumstances penile tumescence. Scoring of the record is performed by a trained technologist and final interpretation is made by the clinical polysomnographer. The final diagnosis is discussed by the multidisciplinary team and recommendations are given at a follow-up visit by the sleep disorders specialist. Therapeutic management includes sleep hygiene, psychological support, pharmacologic treatment, ventllatory assistance and surgical interventions.
\end{abstract}

\section{A clíniea da neurossonologia.}

RESUMO - Desde a aplicação de métodos eletrofisiológicos cedidos pelo laboratório de kEG ao estudo de seres humanos enquanto dormem, a medicina de distúrbios do sono adquiriu organizaçåo necessária para ser acelta na clínica moderna. Embora ainda em evoluçăo, a ciência médica do sono está se tornando cada vez mais ligada às funçóes do cérebro, construindo no território da neurologia uma parcela que lhe é própria, a neurossonologta. Pacientes encaminhados a especialistas em desordens do sono sảo submetidos a avaliaçăo inicial que inclui exames clínico geral e neturológico e, quando indicado, exames especializados. No laboratório de sono, os pacientes são submetidos a registros polissonográficos noturnos e diurnos que abrangem: atividade elétrica cerebral, movimentos oculares, tono muscular, eletrocardiograma, movimentos dos meinbros, respiração, oximetria e, em circunstáncias especiais, tumescência do pênis. O registro ê feito por técnico devidamente treinado e a interpretaçăo final, pelo polissonografista clinico. O diagnóstico é discutido por equipe multidisciplinar e as recomendaçóes são dadas pelo especialista em desordens do sono, em consulta posterior. A conduta terapêutica pode abranger higiene do sono, suporte psicológico, tratamento farmacológico, assisténcia ventilatória e intervenç̃̃es cirúrgicas.

\begin{abstract}
"\$leep is the only voluptuosity offered with liberality by Nature and with equal abundance to each of the human beings, as long as they are not sick." - Gregorio Marañón y Posadillo 6.
\end{abstract}

Not long ago, sleep was taken as a passive state of the brain and the mind, necessary to restore biological energy. The motionless human exhibiting an image of functional retirement was thought to lay in a state of neuronal disconnection, akin to that of the hibernating animal. That image changed swiftly with the application

* Veterans Administration Center and Health Science Center of the State University of New York at Syracuse, and Comnunity General Hospital of Syracuse.

Prof. Antonio Culebras, M.D. - Neurology (127), VAMC - 800 Irving Avenue - syracuse, NY $19210-U S A$ 
of electrophysiologic techniques to the sleeping human. Initial electroencephalographic (EEG) recordings during the night revealed an enormous wealth of brain electrical activity, that occurred with surprising regularity in stages and cycles organized with a predictable architecture. The discovery of rapid eye movement (REM) activity in conjunction with dreaming and muscle atonia gave additional impulse to the study of sleep in the experimental setting and in the human laboratory. The orderly classification and nomenclature of sleep disorders 1, along with the development of clinical polysomnography as an independent technique, finally sanctioned sleep disorders medicine as a scientific discipline. Although still in evolution, the medical science of sleep is becoming increasingly linked to the functions of the brain 3 , carving in the territory of neurology a parcel of its own that we call neurosomnology 5 .

INITIAL CLINICAL EVALUATION - Patients are referred to the Sleep Disorders Center and Laboratory by physicians who have some measure of education in sleep disorders medicine. This information may have come through continuing education courses at national meetings or in the local community, and through press releases and media coverage of sleep disorders in the local newspapers, radio and television stations. The specialists who show most interest in sleep disorders are in addition to the neurologist, the pediatrician, the pulmonologist, the otolaryngologist, the psychiatrist, the psychologist and the urologist. Some patients are referred by family physicians or by internists.

In order to accept the referrals it is important to establish a Sleep Disorders Ciinic. The evaluation is not different from that effected in a regular medical clinic, except that special items of information should be added to the general medical questionnaire. Most important is the patient's sleep/wake schedule with specific questions on snoring, respiratory rhythm, dreaming, falling out of bed, motor events during the night, and subjective feelings of restlessness and restfulness. Questions about daytime sleepiness, scheduled and unscheduled naps, examples of inappropriate sleep, near accidents and outright accidents should complete the inquiry. Information coming from the spouse, mother or close relative is also important and should be actively sought, as well as questions about a possible family trait. A history on sleep hygiene is mandatory and should include regularity on going to bed and getting up, ingestion of stimulant beverages and alcoholic drinks in the evening, pattern of exercise, schedule of meals at night, smoking, television viewing habits particularly in bed, and daytime raps including weekends. The dietary history along with information about recent weight gain is of great importance in the evaluation of the apneas. It is of utmost importance to get a precise history and account of the regimen of medications taken by the patient. Not infrequently such medicines have a strong impact on sleep, alertness, nocturnal apneas and erectile potency. The social, academic and family impact of the sleep disorder is a measure of the gravity and seriousness of the problem.

The physical examination should include a general medical examination, a neurological examination, a brief neurovascular exam and specific investigation of the oral pharynx, mouth, tonsils, tongue, submandibular region and neck. The weight and height should always be recorded, along with a description of the shape of the neck and abdomen. Following the history taking and physical examination the patient is given a brief account of the physician's interpretation and working diagnosis. At this time the patient is told if a sleep test is necessary and a general description of the test is given. In special cases of insomnia or of circadian dysrhythmia, a 14-day evaluation chart of the sleep-wake patterns (Fig. 1) is handed to the patient. Following completion, the chart is returned to the physician for interpretation and permanent documentation of the sleep-wake disturbance as perceived by the patient.

POLYSOMNOGRAPHY - The backbone of sleep disorders medicine is clinical polysomnography, as practiced in the modern sleep laboratory. Polysomnography incorporates techniques borrowed from the EEG laboratory and adds the recording of physiologic parameters that are important to sleep. In our laboratory, the recording room (Fig. 2) is separate from the bedroom by a dividing wall, and both are located in a hospital suite, that while easily accessible to hospital personnel in case of a medical emergency, remains reasonably isolated from corridor traffic and street noises. The bedroom is confortable, clean, quiet, carpeted and air-conditioned with a private, adjacent bathroom. Patients are allowed to smoke if they so desire. The environment is more reminiscent of a tourist hotel than of a hospital bedroom. A low-intensity light television camera mounted on the bedroom ceiling permits con- 


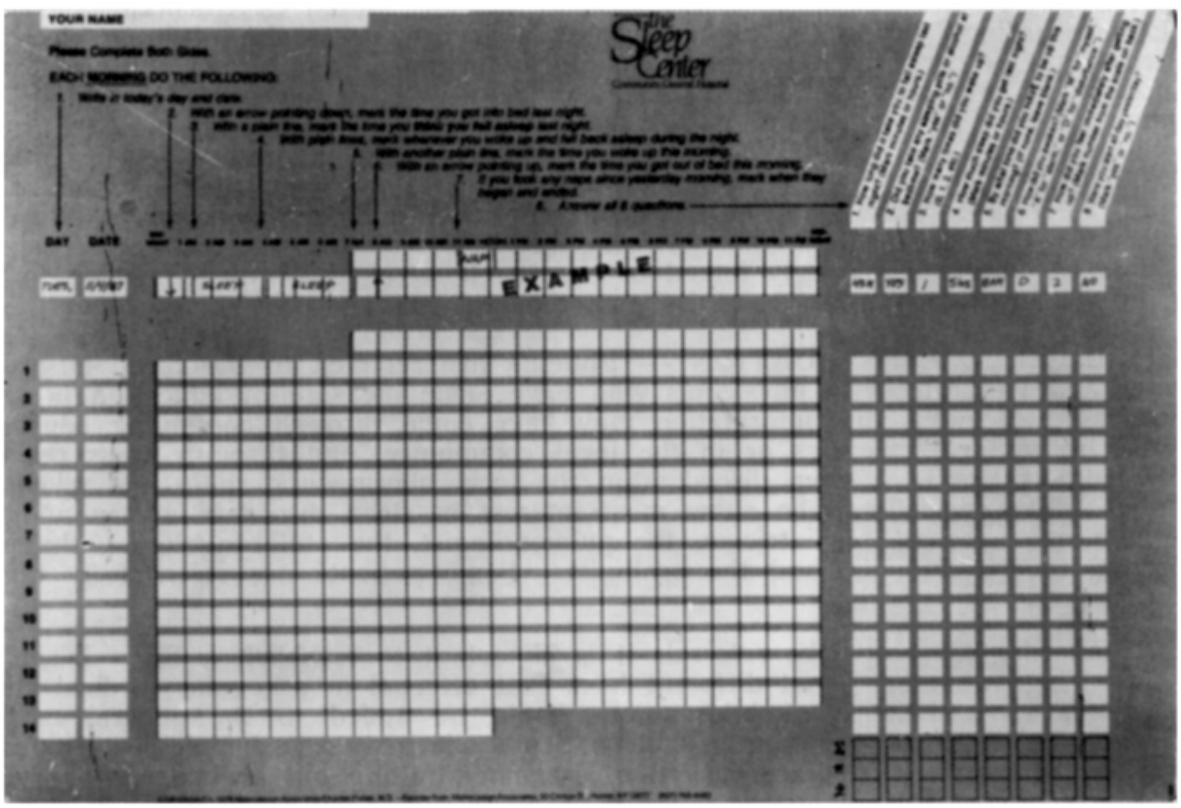

l'ig. 1 - 14-day evaluation chart for documentation of sleep/wake patterns by the patient. There are 14 rows and 24 columns for entries marking the time of going to bed, falling asleep, nocturnal awakenings, final morning awakening, time out of bed and daytime naps. The right hand side of the chart requests information on perception of sleep latency, sleeping pills and alcohol, number of awakenings, perception of nocturnal sleep duration, time scheduled and method used for morning awakening and quality of daytime alertness. The reverse of the chart requests hourly information on quality of alertness over a period of two consecutive days. (Rreproduced by permission of Metrodesign Associates / Charles Pollack, M.D.).

Fig. 2 - Equipment and recording room showing two Nihon-Kohden 12-channel 4912 polygraph machines with video monitor incorporated in the instrument panel. Oximeters are observed above each instrument.

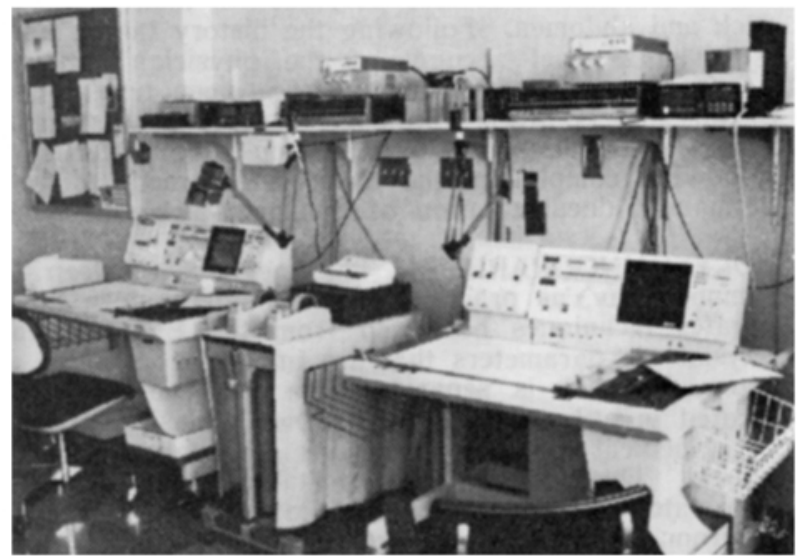


tinuous observation while the patient sleeps in the dark. An intercom allows voice communication with the equipment room where the technician remains during recording hours, observing the patient through the closed-circuit television system. Cables pass from one room to the other through well-concealed portholes in the dividing wall.

The equipment is basically a conventional EEG polygraph with at least four channels of direct current (DC) recording capability. These are necessary to monitor activities of slow frequency and high amplitude such as respirations, chest and abdominal excursions, and oximetry. The conventional paper speed used in our laboratory is $10 \mathrm{~mm} / \mathrm{second}$, resulting in compressed tracings of 30 second epochs (one epoch $=$ one page), that reduce paper costs and volume, and minimize the time spent scoring records, while facilitating the interpretation of slow-frequency events.

Electrodes are perforated gold cups or discs applied with collodion to the skin to assure a satisfactory connection during the 10 or more hours of recording. Disposable silver-silver chloride-pellet electrodes are used over the face, trunk and abdomen. Eight-foot leads allow flexibility of movements during the night. To record nasal and oral ventilation we use air flow monitors that are thermocouples or thermistors applied to the nostril or at the side of the mouth. Bellows connected to an air pressure transducer with output to a DC amplifier record chest and abdominal excursions. Chest activity may also be recorded by surface electromyography (EMG) of intercostal muscles. Miniature microphones serve to monitor snores, snorts and any other vocalizations made during the recording session. The capillary saturation of oxygen is recorded by means of an earlobe or finger oximeter probe, that consists of a photoelectric cell that measures changes in the color spectrum of the circulating hemoglobin. Commercially available devices are used to register penile tumescence during REM-related erections in patients who complain of impotence. Mercury-filled strain gauges placed around the tip and base of the penis generate an electric signal when stretched, that is recorded independently or directly in the polygraphic tracing from a DC amplifier.

The basic protocol consists of seven channels, as follows: three for EEG, two for electrooculography (EOG), one for submental EMG and one for EKG. Depending on the condition to be evaluated a number of parameters are added. The sleep apnea protocol (Fig. 3) consists of the basic protocol plus one channel for nasal-oral ventilaion, one channel for chest excursions, one channel for abdominal excursions
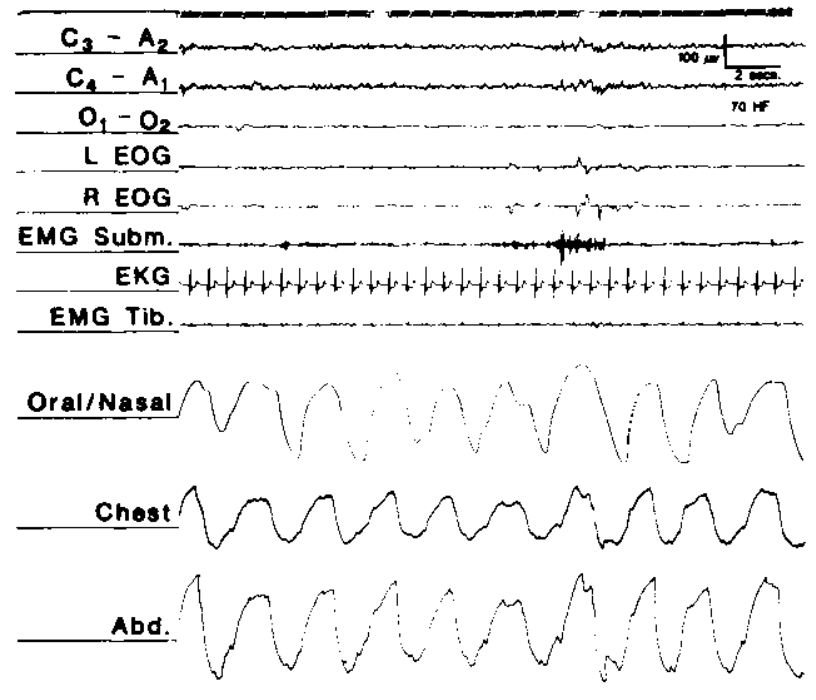

Oxim.
Fig. 3 - Sleep apnea protocol used in our laboratory. The top 6 channels are used to score stages of sleep. Orall nasal ventilation has been incorporated in one channel (paper speed $10 \mathrm{~mm} /$ second). (Abbreviations as in text). 
and one channel for oximetry; an additional channel for recording leg movement activity is customarily added. The leg myoclonus protocol consists of the basic protocol plus two channels for right and left leg movement activity. The impotence protocol incorporates the basic protocol plus two channels for recording expansion of the tip and base of the penis; one channel for leg movement activity is usually added. The seizure protocol utilizes an expanded EEG montage of at least 5 channels that are selected depending on the type of seizure disorder to be studied. Example of a seizure protocol is T3-T4, P3-P4, C3-A2, C4-A1, 01-02 (10-20 international electrode placement system), plus two channels for EOG, one channel for submental EMG, one channel for EKG and two channels for leg movement activity.

Patients report to the sleep laboratory at $8 \mathrm{p} . \mathrm{m}$. to allow enough time for application of monitoring electrodes before bedtime (Fig. 4). Sleep rituals such as brushing teeth, reading in bed, listening to the radio, and even smoking are allowed to facilitate sleep. When the patient is ready the lights are turned off and the recording officially begins. The night technologist remains in the adjacent equipment room operating the recording equipment, noting significant events, observing the patient on the monitor and ready to assist should the patient wish to go to the bathroom or in case of emergency. Training in cardiopulmonary resuscitation is required and ability to recognize medical emergencies is necessary to summon help

Fig. 4 - Clinical polysomnogrophy technologist adjusting nosal und oral thermistors. Observe facial and submental electrodes, and abdominal bellows. Connecting cables are long enough to allow movements during sleep without pulling on electrode box.

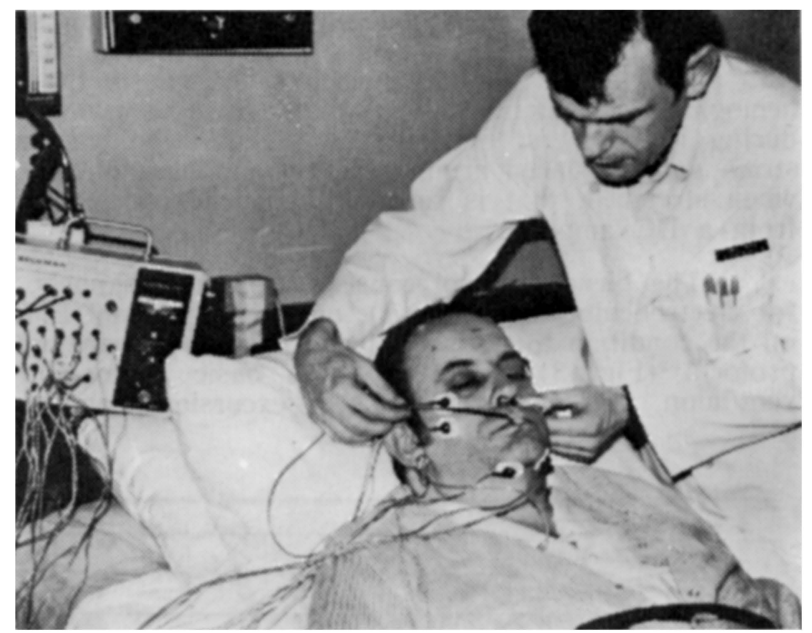

if needed. Technologists are trained to record electrophysiologic parameters and to be able to introduce a modicum of technical flexibility in the recording. They should have some understanding of the clinical situation, to be able to gather the maximum information during the night without direct supervision. Their descriptions of nocturnal events might be crucial to reach a correct diagnosis. In cases where erectile impotence is being evaluated, technologists are required to make direct observations and to measure the buckling resistance of the erect penis, which has been estimated to be in normal males between 500-1500 gram force. Erections are further documented with Polaroid photographic snapshots. Not infrequently nocturnal recordings are followed by serial daytime recordings in the so-called multiple sleep latency test 2 . Two hours following the termination of the nocturnal recording, patients are asked to go to bed again over four segments of at least 20 minutes duration, at two hour intervals starting at $8 \mathrm{am}$. The objective is to measure daytime sleepiness in a variety of conditions and to record daytime REM activity in patients with suspected narcolepsy.

Polysomnographic recordings are scored by the senior technologist in accordance with established quidelines 7. The results are presented to the clinical polysomnographer for review and interpretation along with the videotape. Questionnaires filled out by the patient providing subjective information and pertinent medical data complete the factual material gathered in the sleep laboratory. At the weekly multidisciplinary conference attended by medical consultants, technologists and clinical 
polysomnographer complex cases are reviewed and the meeting serves as a teaching forum. The final polysomnographic report includes all scores and the diagnostic interpretation in consonance with the accepted diagnostic classification of sleep and arousal disorders 1 . Recommendations to referring physicians are given in a covering letter that is separate from the polysomnographic report.

CLINICAL FOLLOW-UP - The patient is scheduled for another follow-up visit with the sleep disorders specialist, as soon as feasible after the results of polysomnography are known. During this office visit the specialist explains in detail the results of the laboratory testing, describes any events that might have occurred and delineates a therapeutic regimen.

Sleep hygiene - Many patients are unaware of the fact that a regular schedule of sleep-times is important to improve the quality of sleep. Mild stimulants such as coffee, tea, chocolate, and coca-cola may alter the ability to initiate sleep. Alcohol in excessive amounts (the equivalent of more than two glasses of wine) shortly before going to bed may work as a powerful hypnotic with a short duration of action, thus allowing the initiation of sleep but promoting early morning awakening once the hypnotic effect disappears. In large amounts, alcohol also disturbs the architecture of the sleep cycles and aggravates sleep apnea. Moderate amounts of exercise facilitate sleep, but exhausting physical activity late in the evening will affect negatively the sleep architecture. Television should be removed from the bedroom and reading should replace it. The bedroom temperature should be kept at a comfortable level and external noises should be blocked whenever possible. Patients who lose their sleep in the middle of the night are allowed to get out of bed and read for a couple of hours. Excessive time spent in bed should be avoided, as well as uncontrolled daytime naps. Sleep restriction therapy for patients with insomnia attempts to make the time in bed more efficient, by limiting the amount of time spent in bed while creating a situation of moderate sleep loss over the first few weeks of treatment. By adjusting the time in bed, an optimal bedtime lenght is reached with the objective of maintaining a good sleep efficiency. Chronotherapy has the objective of synchronizing endogenous pacemakers with external time cues. Patients with delayed sleep phase syndrome have a strong tendency to stay awake until very late hours. Once initiated, their sleep is sound and deep, sometimes to the point of being unable to wake up at conventional times. The treatment strategy is to "reset the clock" by delaying the bedtime three hours every day for a period of eight to ten days, until the conventional times of $10 \mathrm{pm}$ is reached. Thereafter, a rigid schedule of going to bed every night at $10 \mathrm{pm}$ and getting up eight hours later is enforced.

Psychological support - Disturbances of initiating and maintaining sleep are commonly the consequence of a high level of anxiety associated with depression. Patients who are unable to initiate sleep tend to have anxiety predominating, while patients who fall asleep right away to wake up three or four hours later, may have affective depression. Psychotherapeutic support is an important intervention and the necessary adjunct of medication. The most common modalities of treatment include relaxation and biofeedback training, cognitive treatments that desensitize or distract the patient from the insomnia problem, systematic desensitization that involves imagination and muscular relaxation techniques, and stimulus control instructions.

Medication - The most common drugs used by the sleep specialist are: To initiate sleep - Triazolam $0.25-0.5 \mathrm{mg}$ at bedtime (half life 1.5-5 hours). It may improve daytime function.

To initiate and maintain sleep - Temazepam $15-30 \mathrm{mg}$ at bedtime (half-life $0.6-9$ hours). It reduces waking episodes.

To initiate, maintain sleep and reduce daytime anxiety - Flurazepam 15-30 mg at bedtime (half life 47-100 hours, increases with age in men only). Sleep latency decreases on the second night and the drug may accumulate.

Benzodiazepines may cause dependence and withdrawal symptoms that are milder with the long-acting agents. The short-acting agents may cause a withdrawal sleep disturbance that is dose related. To avoid dependence it is important to interrupt the administration of bedtime hypnotics two or three times in the course of the week, so that only 4 or 5 bedtime doses are given in any one week. All hypnotics are respiratory depressants. 
To increase the level of alertness - Methylphenidade (5-10 mg three or four times per day), dexedrine (5-10 $\mathrm{mg}$ three times per day), and pemollne (18.75 $\mathrm{mg}$ one to three tablets in the morning).

To reduce cataplex - The most effective drug is protriptyline, a tricyclic antidepressant with anticholinergic activity, administered at a dose of $5-10 \mathrm{mg}$, two or three times per day; some patients may need up to $60 \mathrm{mg}$ per day. When protriptyline is unavailable or ineffective, imipramine may be used at a dose of $10 \mathrm{mg}$ three times per day, up to a maximum of $200 \mathrm{mg}$ per day. Viloxazine (100-200 $\mathrm{mg} /$ day) and propranolol (120 mg/day) may be effective too. These drugs reduce REM sleep.

\section{MANAGEMENT OF THE SLEEP APNEA SYNDROMES}

\section{Obstructive sleep apnea syndrome (OSAS):}

Nasal continuous positive air pressure (NCPAP) - NCPAP delivers a continuous flow of air at low pressure through a facial mask that covers the nose, while the subject is asleep. The positive pressure ranges between $5-15 \mathrm{~cm}$ of $\mathrm{H}_{2} \mathrm{O}$. This system, which is commercially available, is quite safe but needs to be tested in the sleep laboratory before prescribing its use. It is intended to maintain the airway open during sleep in patients with OSAS, and thus it has been called an "air splint". It is less effective in patients with non-obstructive sleep apnea, although some feel alleviated, possibly because there is an occult obstructive component. In our experience, patients with genuine OSAS of moderate to severe intensity derive major benefit from the nightly application of NCPAP. Rebound REM sleep and increased slow wave sleep, along with improved oxygen saturation and elimination of cardiac disrhythmias mark the objective improvement, already on the first night of testing. Patients report a more restorative sleep and decreased daytime somnolence, and spouses appreciate the eradication of snoring. Some patients with OSAS feel excessively contrained or do not tolerate the face mask for a variety of reasons. These patients are referred to the otolaryngologist for consideration of surgical intervention.

Surgical consultation - It is common to observe in patients with OSAS, particularly if obese, abundant redundant soft tissue partially occluding the oral pharynx. Hypertrophy of the tonsils, a large tongue and a small pharyngeal structure are contributing factors. During sleep the base of the tongue tends to fall back and the relaxation of the pharyngeal musculature particularly in REM sleep precipitate the obstruction. This impedes the passage of air despite the inspiratory effort, unless a partial arousal intervenes. The resection of hypertrophic tonsils in children and in some adults may be curative. In most adult patients with OSAS, tonsillar hypertrophy is not the major factor, and the surgical ablation needs to be extended to the circumpharyngeal soft tissues to be effective. This operation called uvulopalatopharyngoplasty (UPPP) may involve resection of submucous pharyngeal tissue, tonsillectomy and adenoidectomy resulting in an increase of the pharyngeal opening that reduces the inspiratory effort needed to provoke the passage of air during sleep. Furthermore, it eliminates snoring by resecting the redundant tissues that vibrate and cause the typical noise during sleep. The operation is safe in experienced hands, however some patients report post-operative nasal regurgitation of fluids and minor difficulty pronouncing nasal consonants. Thus, it is important to evaluate thoroughly all patients before engaging in this type of surgical intervention, to avoid unnecessary abuses. Tracheostomy remains the operation of choice in patients with advanced OSAS complicated with pulmonary hypertension and ominous cardiac dysrhythmias. If the patient improves following the operation, an UPPP may be considered. In rare cases of micrognathia, retrognathia and related malformations of the facial structure, osteotomy and surgical advancement of the mandible may correct the pharyngeal stenosis sufficiently to improve the OSAS. Other methods include the tongue retaining device that prevents the base of the tongue from falling back and orthodontic treatments.

General measures - Weight loss is a long term objective that needs to be pursued vigorously, but unfortunately is difficult to attain unless drastic and aggressive measures are implemented. Gastric stapling and gastric balloons have been used in severe cases. Patients with OSAS should avoid the use of sedatives and alcohol at night. Sometimes, preventing the patient from sleeping on his back (by sewing a tennis ball to the back of the pajamas) is enough to eliminate snoring. Protriptyline reduces the severity of obstructive apnea episodes and is a useful adjunct in cases of mild intensity. 
Non-obstructive sleep apnea: The treatment of the non-obstructive (central) sleep apnea syndrome is a vexing problem. The obstructive component may respond to protriptyline or NCPAP, and thus these modalities should be tested. Acetazolamide $250 \mathrm{mg}$ four times per day may reduce the severity of apneas. Some patients respond to the nocturnal administration of low-flow oxygen. In severe cases tracheostomy, mechanicaí ventilation and diaphragmatic pacing should be considered.

Specific situations: Night terrors respond to small amounts of diazepam, $2-10 \mathrm{mg}$ administered at bedtime. Nightmares that are REM related may be reduced or eliminated with protriptyline $5-10 \mathrm{mg}$ at bedtime. Primary enuresis that fails to respond to behavioral modification may be reduced with imipramine $25-75 \mathrm{mg}$ at bedtime. Leg myoclonus is controlled with clonazepam $0.5-2 \mathrm{mg}$ at bedtime. Somnambulism not responsive to behavioral moditification is abolished in many instances with diazepam $2-10 \mathrm{mg}$ at bedtime. Phantasmagorias associated with REM without atonia in the REM motor behavior disorder are well controlled with clonazepam 0.5-2 mg at bedtime 4. Triazolam alleviates the distortion caused by acute time shifts as in the "jet-lag" syndrome, when given $0.5 \mathrm{mg}$ at the "new bedtime".

\section{RFFERENCES}

1. Assuciation of Sleep Disorders Centers - Diagnostic Classification of sleep and Arousal Disorders. Ed 1. Prepared by the Sleep Disorders Classification Cormittee, (H.P. Rotfwarg, chairman). Sleep 2:1, 1979.

2. Association of Sleep Disnrders Centers Task Force on Daytime Sleepiness - Guidelines for the multiple sleep latency test (MSLT): a standard measure of sleepiness. Sleep 9:519, 1986.

3. Culebras A - Sleep disorders medifine: how neurologlcal? Arch Neurol 42:600, 1985.

4. Culebras A - REM sin atonia y fantasmagorias. Rev Neurol Argent 14:161, 1988.

5. Culebras A, Magaña $\mathbb{R} \rightarrow$ Neurologic disorders and sleep disturbances, In Joynt $R$ (ed): Seminarg in Neurology, Vol. 7. Thieme-Stratton, New York, 1987, pg 277.

6. Marañon y Posadillo G - La Fisiología y Patología del Sueño. Discurso de Recepción del Doctor Gonzalo Rodriguez Lafora y Contestación del Doctor Marafion. Academia Nacional de Medicina, Madrid, 14 de nayo de 1933.

7. Rechtschaffen A, Kales A (eds) - A Manual of Standardized Terminology, Techniques and Scoring System for Sleep Stages of Human Subjects. BIS/BRI, UCLA, Las Angeles, 1968. 